\title{
Review \\ A Review of Sintering-Bonding Technology Using Ag Nanoparticles for Electronic Packaging
}

\author{
Jianfeng Yan
}

check for updates

Citation: Yan, J. A Review of Sintering-Bonding Technology Using Ag Nanoparticles for Electronic Packaging. Nanomaterials 2021, 11, 927. https://doi.org/10.3390/ nano11040927

Academic Editor: Stefano Agnoli

Received: 11 March 2021

Accepted: 3 April 2021

Published: 6 April 2021

Publisher's Note: MDPI stays neutral with regard to jurisdictional claims in published maps and institutional affiliations.

Copyright: (C) 2021 by the author. Licensee MDPI, Basel, Switzerland. This article is an open access article distributed under the terms and conditions of the Creative Commons Attribution (CC BY) license (https:// creativecommons.org/licenses/by/ $4.0 /)$.
Key Laboratory for Advanced Materials Processing Technology, Ministry of Education of China, State Key Laboratory of Tribology, Department of Mechanical Engineering, Tsinghua University, Beijing 100084, China; yanjianfeng@tsinghua.edu.cn

\begin{abstract}
Metal nanoparticles (NPs) have attracted growing attention in recent years for electronic packaging applications. Ag NPs have emerged as a promising low-temperature bonding material owing to their unique characteristics. In this study, we mainly review our research progress on the interconnection of using polyol-based Ag NPs for electronic packaging. The synthesis, sinteringbonding process, bonding mechanism, and high-temperature joint properties of Ag NP pastes are investigated. The paste containing a high concentration of Ag NPs was prepared based on the polyol method and concentration. A nanoscale layer of organic components coated on the NPs prevents the coalescence of Ag NPs. The effects of organic components on the bondability of the Ag NP paste were studied. Compared to the aqueous-based Ag NP paste, the polyol-based Ag NP with the reduction of organic component can improve the bondability, and the coffee ring effect was successfully depressed due to the increased Marangoni flow. The sintering behaviors of Ag NPs during the bonding process were investigated using the classical sphere-to-sphere approach. The mechanical property of joints using this $\mathrm{Ag}$ paste was better than that using $\mathrm{Pb}_{95} \mathrm{Sn}_{5}$ solders after storage at high temperatures. The sintering-bonding technology using polyol-based Ag NPs was helpful to the low-temperature interconnection for electronic packaging applications.
\end{abstract}

Keywords: Ag NP pastes; low-temperature interconnections; sintering mechanisms; joint performances; electronic packaging

\section{Introduction}

The attachment material plays an important role in the high-power electronic packaging applications, which can ensure the reliability and performance of devices [1-6]. Metal nanoparticles (NPs) have attracted growing attention in recent years owing to their unique characteristics such as low melting temperature and high diffusion coefficient, which differ from those of bulk materials [7-12]. The sintering and bonding of metal NPs at low temperatures has been demonstrated and is promising for applications in flexible electronic devices, including organic electronics and flat-panel displays [13-16].

Ag NP pastes have become the suitable choice for a new type of lead-free interconnection materials because of their high electrical conductivity, good fatigue performance, and high melting point [17-21]. They can work at a higher temperature than the bonding temperature with enhanced shear strength. Compared to other materials, Ag has a higher tensile strength, which can prevent the mechanical properties of Ag NP pastes from degeneration in a harsh environment. Owing to their good mechanical properties, Ag NP pastes exhibit higher bonding strength. The synthetic method and sintering process affect the bonding quality of Ag NP pastes, which dominate the application of NP pastes. It has been reported that adding organic components to Ag NPs can prevent self-aggregation in the traditional synthesis process [22-26]. However, this has a negative effect on sintering because the added organic components remain in the bonding layer [27]. They prevent surface and lattice diffusions from the surface and grain boundary of NPs during the sintering process, leading to a low strength bonding. There were many studies on improving the 
sintered properties of Ag NP pastes. To address this problem, a method for preparing Ag NP pastes based on the polyol method was proposed, and it was found that reducing the organic components in NP pastes benefitted the sintering-bonding process [8,19,27-29].

Therefore, this review mainly discusses improving the performance of bonding joints using the polyol-based Ag NP pastes of our research. Firstly, we introduce the progress in the synthesis of Ag NPs and the sintering-bonding process. Emphasis is placed on the polyol synthesis method and the effects of organic components on the bondability of the Ag NP paste, such as the coffee ring effect. Then, based on the sphere-to-sphere models, the sintering-bonding mechanisms were investigated. Surface diffusion and volume diffusion are found. Afterward, the applications of sintered Ag NP pastes in high-temperature environments were presented. Finally, we summarize our findings and the challenges that should be addressed for future research.

\section{Interconnections Using Ag NP Pastes}

\subsection{Description of the Synthesis and Sintering of Ag NP Pastes}

A metal NP paste is prepared by combining organic components with metal NPs to prevent agglomeration $[22,23,25,26]$. However, the addition of organic components inhibits the sintering process. A method for preparing high-concentration Ag NP pastes was developed based on the polyol method [30]. In the process, the NP paste was synthesized by chemical reduction, then the paste was concentrated. Figure 1 shows a schematic illustration of the bonding process using metal NP pastes in the air. First, high-concentration Ag NP pastes coated with a thin organic shell were prepared, where the organic content was lower than that of the metal-organic compound. Next, during heat processing, the organic components were decomposed and volatilized. The surface reactivity of Ag NPs re-emerged owing to the high specific surface area. Through atomic diffusion, bridges between NPs were formed, and the neck started to grow; then, the Ag NPs were sintered, promoting bonding. Note that the sintering-bonding process was dependent on the organic components, assistant pressure, and bonding temperature, which were studied in the following sections.

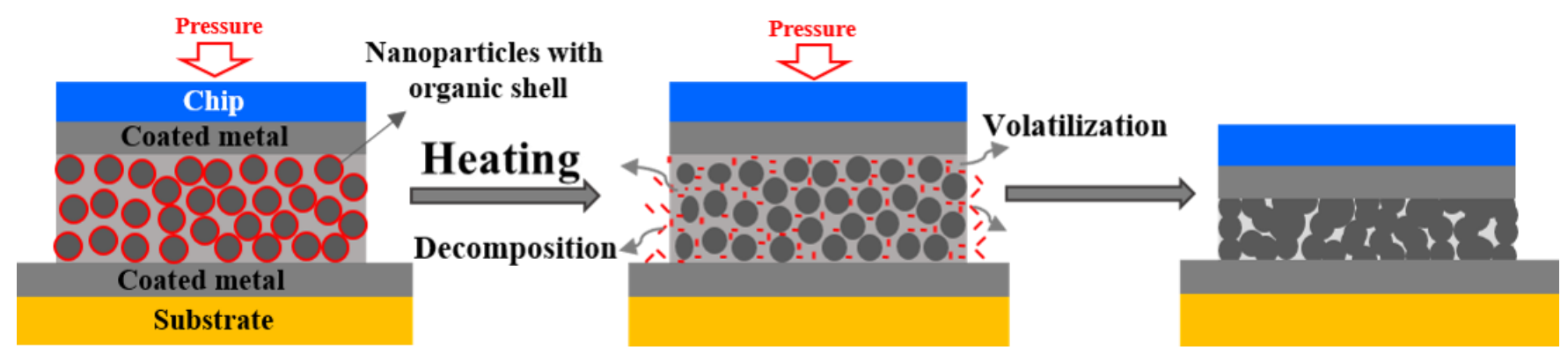

Figure 1. Illustration of the sintering-bonding process using polyol-based Ag NPs.

\subsection{Synthesis of Ag NP Pastes and Effect of Organic Components}

Metal NPs have been prepared by various methods, such as chemical reduction [31], light-induced reduction [32,33], electrochemical methods [34], template methods [35], laser processing methods [36-39], and ultrasonic and microwave methods [40-43]. Table 1 summarizes the electrical conductivity of mainly typical die-attach systems, and it is easy to find that the electrical conductivities of Ag NP pastes are far higher than the other typical die-attach systems. The chemical reduction method is most commonly used in the synthesis of Ag NPs $[30,44]$. In this process, a solution of ethylene glycol and $\mathrm{AgNO}_{3}$ was prepared, along with a separate solution of ethylene glycol and polyvinyl pyrrolidone (PVP). After heating these solutions to the desired reaction temperature $\left(160^{\circ} \mathrm{C}\right)$, the PVP solution was dropped into the $\mathrm{AgNO}_{3}$ solution. Upon reaction completion, the solution was cooled by adding deionized water. Without adding organic components, the paste was prepared by concentrating the Ag NP solution. PVP was used as a protecting agent in the 
synthesis, which affects the properties of the resulting NP pastes and the following bonding processes [27]. Figure 2a-c shows the scanning electron microscopy (SEM) images of Ag NPs synthesized using different concentrations of PVP. With low concentrations, $(0.045 \mathrm{M})$, the Ag NPs were not completely coated by PVP and tended to grow into larger NPs with diameters of $90 \mathrm{~nm}$. By increasing the concentration $(0.45 \mathrm{M})$, more Ag NPs were coated by PVP, and their size was reduced (diameter: $40 \mathrm{~nm}$ ). At an even higher concentration of PVP $(1.35 \mathrm{M})$, smaller NPs were obtained. Therefore, the PVP concentration clearly plays a vital role in the synthesis process of Ag NPs, preventing self- aggregation and reducing NP sizes.

Table 1. Electrical conductivity of mainly typical die-attach systems.

\begin{tabular}{ccc}
\hline Die-Attach Systems & Electrical Conductivity, $\times \mathbf{1 0}^{\mathbf{5}} \mathbf{( \mathbf { ~ } \mathbf { ~ m } ) ^ { \mathbf { - 1 } }}$ & Ref. \\
\hline Ag NP paste & 2.5 & {$[45]$} \\
Cu micro-paste & 1.3 & {$[46]$} \\
Ag-Al NP paste & 1.01 & {$[47]$} \\
Au solder alloys & $0.2-0.4$ & {$[48,49]$} \\
Sn-Pb solder alloys & $0.5-0.9$ & {$[50]$} \\
\hline
\end{tabular}
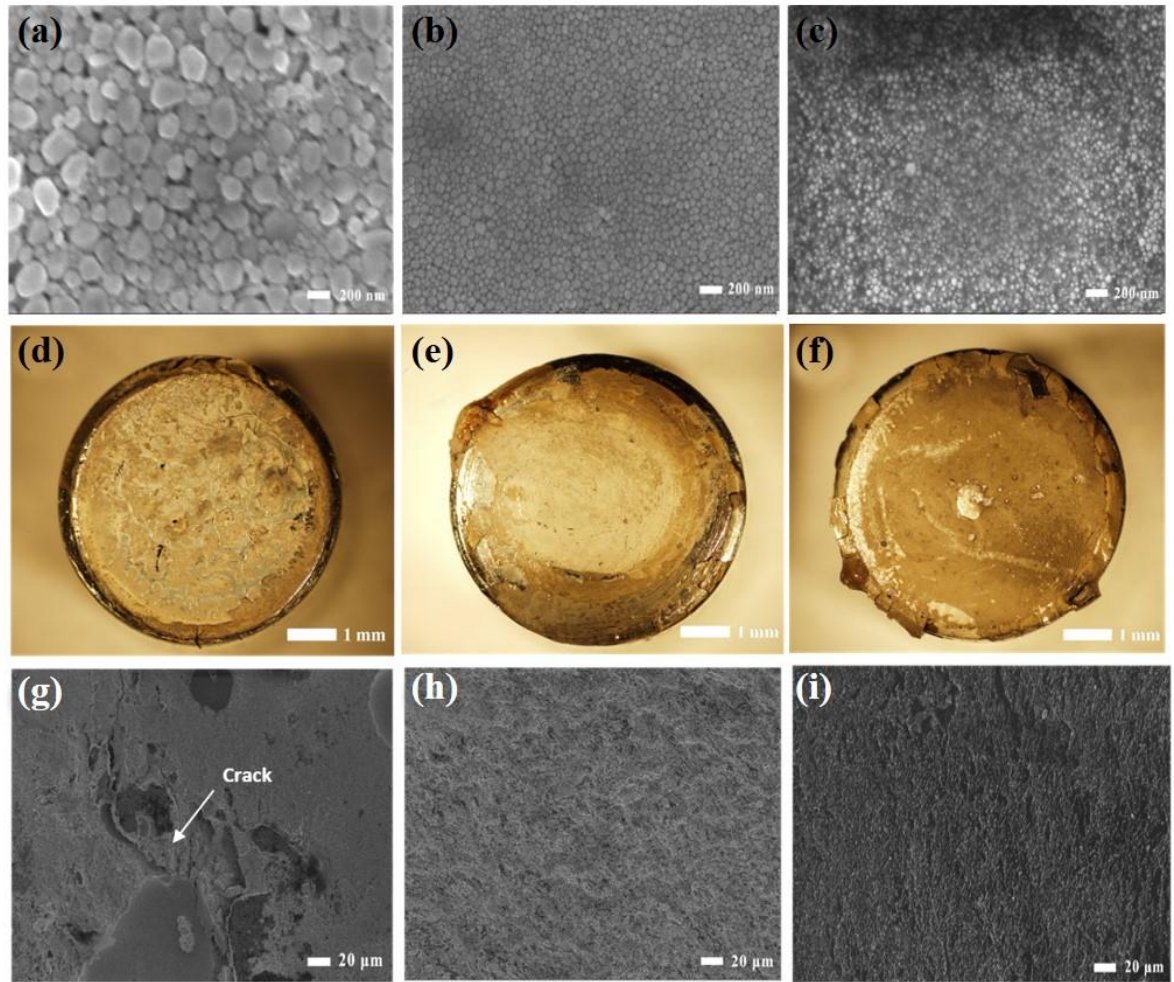

Figure 2. (a-c) SEM images of synthesized Ag NPs. (d-f) Optical images of the fractured bonded joints. (g-i) SEM images of the joints containing Ag NP pastes with PVP concentrations of $0.045 \mathrm{M}$, 0.45 M, 1.35 M. Reprinted/Adapted with the permission from Yan, J (2012). Copyright 2012 IOP Publishing [27].

The viscosities of the Ag NP solutions were measured. With the increase in PVP concentration from $0.045 \mathrm{M}$ to $1.35 \mathrm{M}$, the viscosity of the Ag NP solutions increased from $4.2 \mathrm{cP}$ to $6.0 \mathrm{cP}$, suggesting that the viscosity is highly dependent on the PVP concentration. In addition, the shear strengths of these $\mathrm{Ag}$ NP pastes were evaluated; at a bonding pressure of $5 \mathrm{MPa}$, the shear strengths were 26,50 , and $5 \mathrm{MPa}$. The concentration of PVP affects the size, viscosity, and bondability of the paste. Figure $2 d-f$ show the fracture appearances of copper-disc joints bonded using Ag NP paste. The corresponding SEM images are shown in Figure $2 \mathrm{~g}-\mathrm{i}$. For the joint using Ag NP paste with a PVP concentration of $0.045 \mathrm{M}$, the fracture is fairly rough, and many cracks are observed in the sintered layer. This results 
from the low viscosity of Ag NP paste. Due to cracks in the sintered layer, the average joint strength is about $26 \mathrm{MPa}$. When Ag NP pastes containing PVP concentrations of $0.45 \mathrm{M}$ and $1.35 \mathrm{M}$ were used as adhesive materials, dense and smooth fracture surfaces were observed. The dimple structure was easily observed, which indicates that a good joint was formed. The function of PVP in Ag NP paste is to adjust viscosity and prevent the sintered Ag layer from cracking. Because cracking of the Ag NP paste was effectively prevented, the bonding strength of the Ag NP paste with a PVP concentration of $0.45 \mathrm{M}$ remarkably increased to $50 \mathrm{MPa}$, indicating that the Ag NP paste has improved adhesion with PVP incorporation. Figure 2f,i show the fracture surfaces of Ag NP pastes with a PVP concentration of $1.35 \mathrm{M}$. Given the noticeable fracture traces, the joint strength is as low as $5 \mathrm{MPa}$. According to qualitative energy-dispersive X-ray (EDX) analysis of the joint using different Ag NP pastes, only the pure Ag element was detected for Ag NP pastes with PVP concentrations of $0.045 \mathrm{M}$ and $0.45 \mathrm{M}$, indicating that no organic material remained in the bonding layer. In addition to the Ag peak, a larger carbon peak appeared in the spectrum of the Ag NP paste with a PVP concentration of $1.35 \mathrm{M}$, indicating that organic matter still remains. Organic materials have a negative impact on the formation of joints because they prevent surface diffusion during the sintering, resulting in low bonding strength. The joint strength visibly decreased in this case. According to the results, PVP can prevent both the aggregation of Ag NPs and cracking of the dried Ag NP paste during the bonding process. The Ag NP paste may crack if the PVP concentration is too low. In contrast, with a high concentration of PVP, the bonding quality may be worsened by the residual organic components. An optimized PVP concentration is vital to the sintering quality of Ag NP pastes.

\subsection{Sintering-Bonding Process of Ag NP Pastes}

The sintering-bonding process of Ag NP pastes has recently become a hot topic [51]. The research objective is to develop a low-temperature bonding and enhance the bondability and robustness of joints. To prevent the aggregation of metal NPs, different organic components are added $[22,23,25,26]$. However, these organic components are detrimental to the sintering process. In order to remove the organic molecules, the bonding process is usually carried out at an annealing temperature of $250-350{ }^{\circ} \mathrm{C}$ with an auxiliary pressure of 1-20 MPa $[19,22,23,25,26,52,53]$. Nevertheless, the use of auxiliary pressure will limit the widespread application of this technology, especially in flexible electronic devices. Without auxiliary pressure, it is still possible to use highly concentrated Ag NP pastes to realize low-temperature interconnection [8]. As shown in the SEM images (Figure 3a), Ag NPs are mainly spherical with an average diameter of $\approx 35 \mathrm{~nm}$. Figure $3 \mathrm{~b}$ shows a transmission electron microscopy (TEM) image of Ag NPs. A transparent organic shell with a thickness of 1-2 $\mathrm{nm}$ can be seen on the NP surface, whose role is to prevent the aggregation of Ag NPs. Figure $3 \mathrm{c}$ displays the SEM image of Ag NPs (annealed at $250{ }^{\circ} \mathrm{C}$ in air for $30 \mathrm{~min}$ ). Clearly, sintering of the NPs occurred even without external pressure, which may be caused by capillary pressure between the contacted NPs. These NPs are connected by their surfaces instead of melting completely, resulting in a denser connected structure. The sintering process is critical for the bonding. To study the interface bonding mechanism of this Ag NP paste, the bonding interface was observed by TEM at $250{ }^{\circ} \mathrm{C}$ and $5 \mathrm{MPa}$. The TEM image (Figure 3d) indicates that using the Ag NP paste as a sintering material achieves direct metal bonding. 

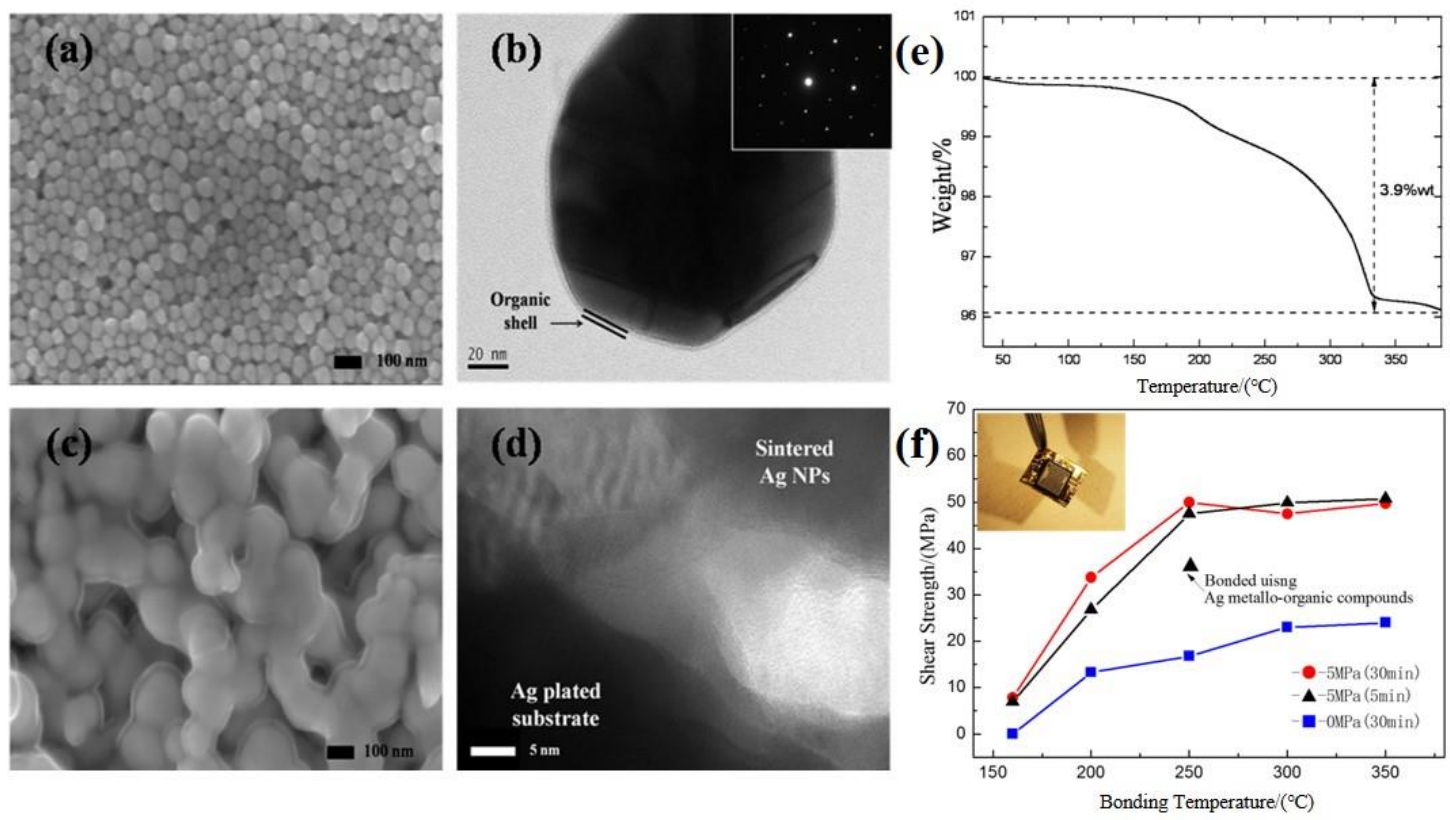

Figure 3. (a) SEM and (b) TEM image of Ag NPs. (c) SEM image of the Ag NP paste. (d) TEM image of the bonding interface. (e) Thermogravimetric analysis (TGA) of the Ag NP paste in air. (f) Shear strength of Ag pastes as a function of sintering temperature with external pressure. Reprinted/Adapted with the permission from Yan, J (2012). Copyright 2012 Elsevier Ltd. [8].

The organic content of the Ag NP paste was characterized by thermogravimetric analysis (TGA) which is a quantitative analytical technique that monitors the mass of a sample as a furnace ramps temperature under a stable or changing gas flow, as shown in Figure 3e. When the temperature rises from $40{ }^{\circ} \mathrm{C}$ to $400{ }^{\circ} \mathrm{C}$, the weight of the dry paste gradually decreases. The evaporation and decomposition of organic components contribute to the weight loss. According to these results, the paste is composed of $\approx 3.9 \%$ organic components by mass, which is much lower than the organic content found in conventional Ag paste (15\% by mass) [22]. Therefore, the Ag content (96.1\%) in the Ag NP paste is significantly higher than that of conventional $\mathrm{Ag}$ paste. It can be demonstrated that the improvement in adhesion is a result of a lower organic content because a higher content adversely affects the sintering process. The shear strength of the joints changes with the increase in bonding temperature under different pressures and holding times. As shown in Figure 3f, for holding times of $5 \mathrm{~min}$ and $30 \mathrm{~min}$ under $5 \mathrm{MPa}$, a shear strength (above $30 \mathrm{MPa}$ ) can be induced even at $200{ }^{\circ} \mathrm{C}$. With the increase of bonding temperature to $250{ }^{\circ} \mathrm{C}$, the shear strength increases to $50 \mathrm{MPa}$, demonstrating its better mechanical behavior compared to that of the conventional Ag paste [22]. Specifically, when the pressure decreases to $0 \mathrm{MPa}$, a robust joint with $10 \mathrm{MPa}$ shear strength is formed at a bonding temperature of $200{ }^{\circ} \mathrm{C}$; the shear strength increases to greater than $20 \mathrm{MPa}$ at $300{ }^{\circ} \mathrm{C}$. The variation of shear strength with bonding temperature under different pressures and holding times confirms the improved bondability of the Ag NP paste owing to the lower organic content. Additionally, an Ag NP-pasted chip bonded to a flexible circuit board is illustrated in the inset at $200{ }^{\circ} \mathrm{C}$ and $0 \mathrm{MPa}$. Thus, a pressureless bonding process can be achieved by the reduction of organic components in metal NP paste.

The bondability of robust joints is determined by uniformities of deposition layers during bonding with Ag NPs. The well-known "coffee ring effect" $[54,55]$ influences the bonding of metal NPs at low temperatures. This effect occurs when the suspension particles are pushed to the wetting edge due to the different evaporation rates of colloid solutions. A similar phenomenon is observed for Ag NPs, in which an inhomogeneous distribution of aqueous-based pastes occurs during the bonding process at low temperatures, affecting the bonding quality. Subsequently, the mechanical strength of those joints is dramatically 
reduced because of the reduction in connection area. On the contrary, an improved bondability of joints has been observed when the inhomogeneous distribution of NPs is depressed during the bonding process. The introduction of polyol-based Ag paste depresses the coffee ring effect significantly because the Marangoni flow increases during the bonding process, and the mechanical strength can be improved accordingly. Ag NPs adopt different geometrical scales when synthesized via aqueous or polyol methods. The chemical reduction of $\mathrm{AgNO}_{3}$ is used to prepare aqueous-based Ag NPs with sodium citrate dehydrate acting as a reducing agent. The Ag NPs synthesized by the aqueous method are spherical with a mean diameter of $45 \mathrm{~nm}$. The diameter of Ag NPs synthesized by the polyol method decreases to $35 \mathrm{~nm}$, as shown in Table 2. Ag NP powders consist of micro-sized, flake-like pellets of tightly packed Ag NPs. These Ag NP powders can be accumulated by drying the aqueous-based $\mathrm{Ag} \mathrm{NP}$ paste at $60^{\circ} \mathrm{C}$ in a glass beaker.

Table 2. Properties of Ag NP pastes prepared with three different methods.

\begin{tabular}{ccccc}
\hline & Size Diameter & $\begin{array}{c}\text { Coffee Ring } \\
\text { Effect }\end{array}$ & Joints & $\begin{array}{c}\text { Shear Strength } \\
\text { (MPa) }\end{array}$ \\
\hline Aqueous-based Ag NPs & $45 \mathrm{~nm}$ & Existence & Gaps & 12 \\
Polyol-based Ag NPs & $35 \mathrm{~nm}$ & Elimination & No defects & 50 \\
Ag NP powders & Micro-sized & Elimination & Voids & 12 \\
\hline
\end{tabular}

In order to obtain a high-quality joint, it is critical to deposit the Ag NPs uniformly before joint assembly and bonding. Two kinds of Ag NP pastes (aqueous and polyol pastes) were placed on the copper substrates and evaporated in air $\left(60^{\circ} \mathrm{C}\right)$ to compare their deposition behavior. Coated circular areas $3-5 \mathrm{~mm}$ in diameter were obtained after drying the deposited Ag NPs. The aqueous Ag NPs accumulated at the rim of the coated circular areas can be attributed to the coffee ring effect [56]. After placing a droplet of Ag NP paste on the substrates, the evaporation rate at the edge was faster than that at the center [57], thus more solution evaporated from the edge. The contact line of the droplet was pinned during the evaporation, so the radius of the droplet could not shrink. The water lost at the edge could be replaced by drawing the solution from the center. The Ag NPs were carried from the center to the rim of the droplet with the water, forming a coffee ring of Ag NPs. On the other hand, the coffee ring effect could be reduced by using a polyol-based Ag NP paste. The elimination of the coffee ring can be explained by the generated Marangoni flow. The solvent for the polyol Ag NP paste is a mixture of water and ethylene glycol. Since the water and ethylene glycol have different boiling points and surface tension, Marangoni flow can be generated during the drying process of the Ag NP paste $[58,59]$. In addition to the convective flow, a concentration gradient was also induced by the enhanced evaporation of ethylene glycol. Owing to the different evaporation rates of water and ethylene glycol, a Marangoni-type flow from the edge to the center can also be induced. Therefore, the coffee ring effect can be reduced.

A uniform Ag layer is critical for good bondability. Figure 4 shows the optical images of the joints using different bonding materials. As shown in Figure 4a, a gap between $\mathrm{Cu}$ discs was observed in the joints using aqueous-based Ag NP pastes. The gap formation is related to the uniform deposition of the Ag NPs due to the coffee ring effect. In order to reduce this effect, dried Ag NP powders were used as the connecting material. As shown in Figure $4 \mathrm{~b}$, the coffee ring disappeared due to the solid state of the Ag NPs. However, voids were evident in the sintered layer of Ag NP powders. Figure 4c shows the joint using the polyol-based Ag NP paste. A dense and uniform sintered Ag layer without obvious cracks and voids was formed. This dense and uniform structure indicates that the bondability of polyol-based Ag NP paste is better than that of aqueous Ag NP paste or powder. The effects of different bonding materials on the shear strength were evaluated. Using the same bonding parameters, a drastic enhancement in the shear strength of joints is observed using the polyol-based Ag NP paste. The average shear strength using polyolbased paste reached $50 \mathrm{MPa}$, while the joints bonded using aqueous-based Ag NPs and 
powders possessed similar shear strengths of $\approx 12 \mathrm{MPa}$. Therefore, uniform deposition of the NPs plays a vital role in improving the joint strength. The distinct shear strength can be explained by the coffee ring effect and the microstructures of the shear joints. The interfacial strength is governed by the microstructures on the interface [1]. The SEM images of the microstructures on the fractured surface are shown in Figure $4 \mathrm{~d}$. The joints using aqueous-based Ag NPs possessed smaller connection areas due to the coffee ring effect. Although the coffee ring effect can be depressed using Ag NP powders, the shear strength remained relatively low due to the large number of voids in the sintered layer, as shown in Figure 4e. In addition, it can be seen in the SEM images that the fractured surface is partially located at the interface, which indicates a physical rather than metallurgical bonding of the sintered joints. The fractured surface of the joints using polyol-based Ag NPs is shown in Figure 4f. The coffee ring effect was prevented, and the connection area was increased by using polyol-based Ag NP paste. Denser microstructures and lower porosity at the fractured surface were observed. Both factors led to the shear strength increase. The fracture mainly occurred in the Ag NP layer, which confirms the improvement of the interfacial strength. According to the tensile failure traces, a ductile fracture mechanism was operative in the sintered NP layer [60]. Overall, the joint strength can be increased by depressing the inhomogeneous distribution of NPs.
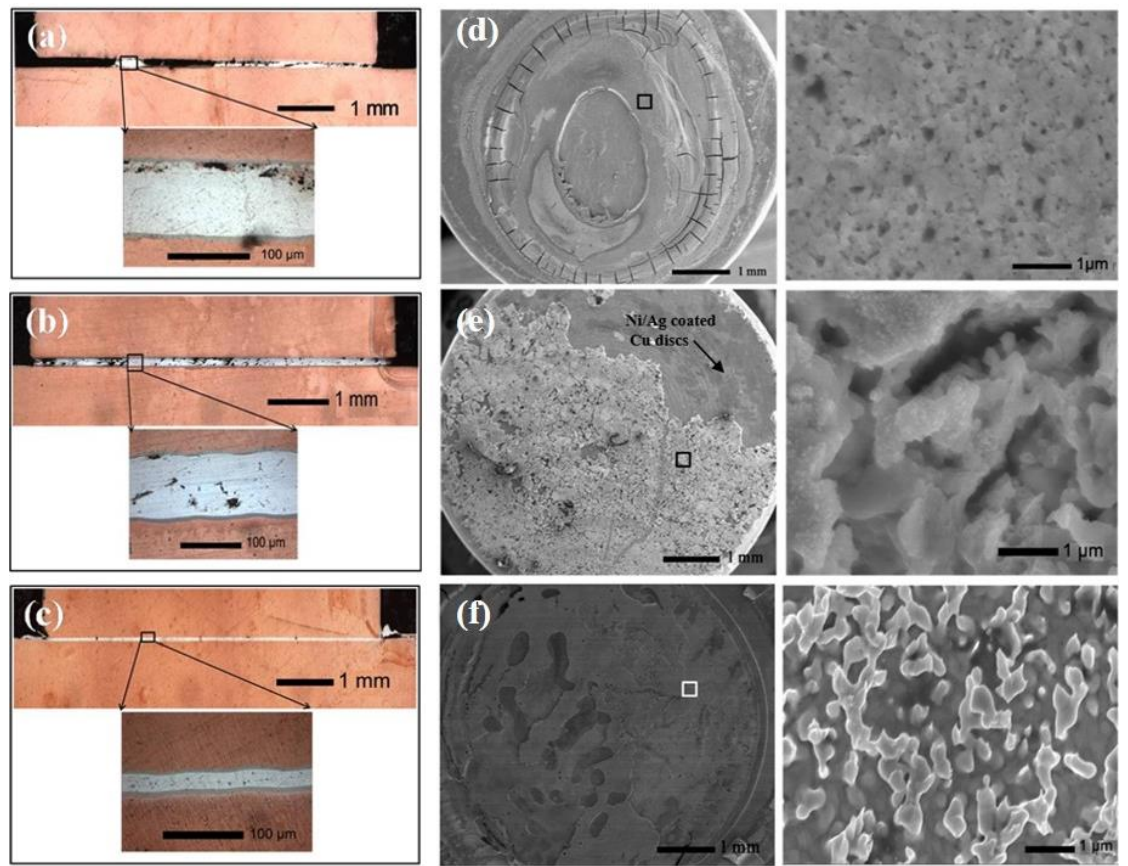

Figure 4. $(\mathbf{a}-\mathbf{c})$ Optical images of the joint cross-sections, and (d-f) SEM images of the shear joints using aqueous-based Ag NP paste, Ag NP powders, and polyol-based Ag NP paste. Reprinted/Adapted with the permission from Yan, J (2012). Copyright 2012 Springer Nature [61].

\subsection{Sintering Mechanisms of $\mathrm{Ag} N \mathrm{~N}$ Pastes}

An understanding of the underlying mechanisms of metal NP sintering is necessary in the fields of electric packaging and manufacturing $[8,22,53,62-70]$. The sintering process of Ag NPs has been discussed using the classical sphere-sphere model [71], and the relationship between the mechanical properties and microstructures was investigated. The sintering process of NPs is crucial in the formation of bonding joints because fractures typically occur in the sintered NP layer [22,53]. The sample was prepared by sintering Ag NPs in air. As shown in Figure 5a-c, two spherical Ag NPs were sintered, and the "neck" between the two was formed after heating. 

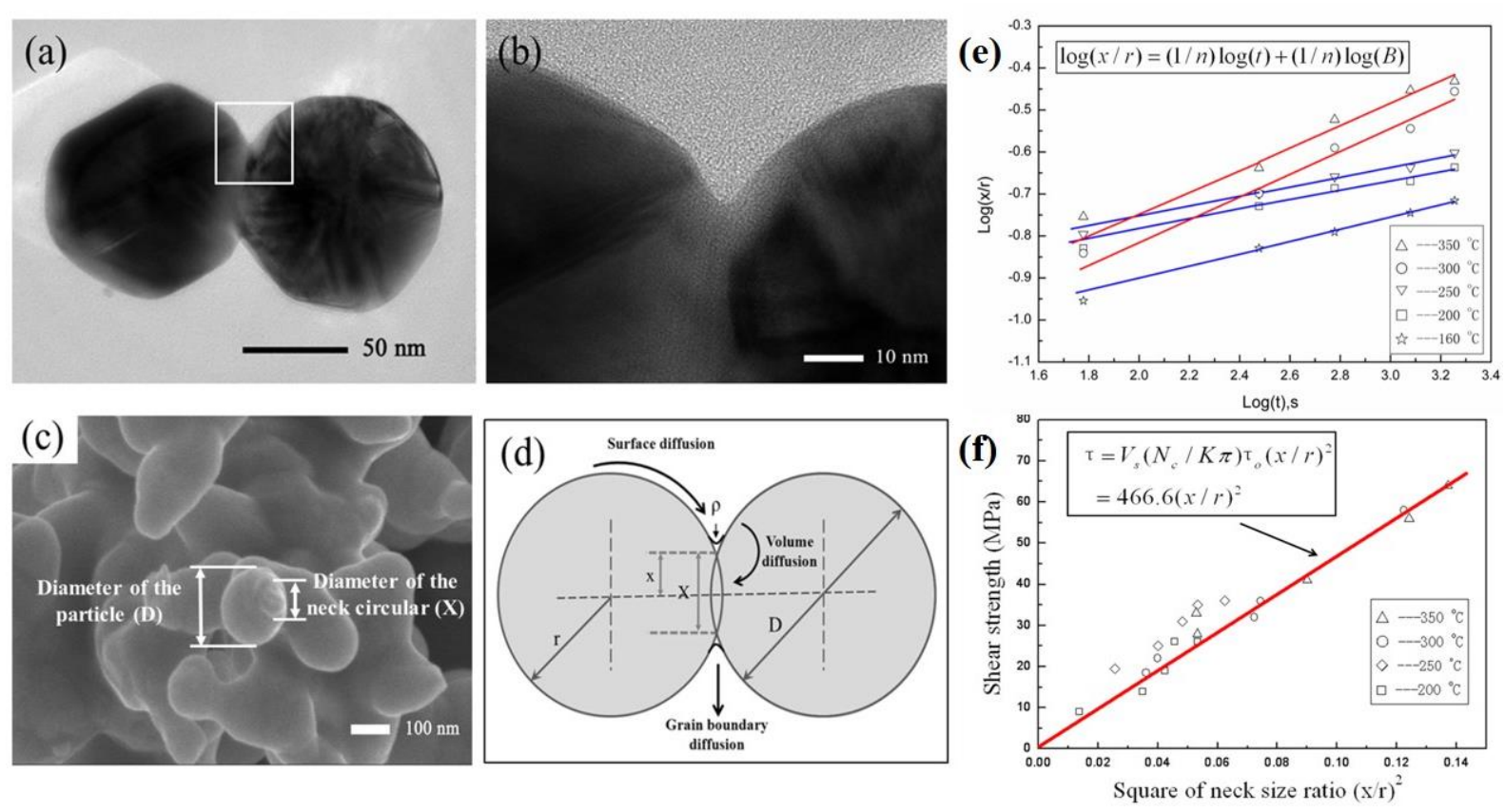

Figure 5. (a,b) TEM images and (c) SEM image of the sintering of two adjacent Ag NPs. (d) Schematic of the sphere model, where $\mathrm{D}$ is the diameter of the NP and $\mathrm{X}$ is the diameter of the interparticle neck. (e) Neck growth kinetics at different temperatures. (f) The relationship between the joint strength and the square of the neck size ratio $(x / r)^{2}$. Reprinted/Adapted with the permission from Yan, J (2015). Copyright 2015 Springer Nature [71].

Multiple models have been developed in order to explain the bonding of NPs [72-74], among which the classical sphere model proposed by Frenkel focused on the contact of two metal NPs [72]. As shown in Figure 5d, at the initial stage, the model consists of two spheres having equal sizes. The neck between the two spheres (with a diameter of $\mathrm{D}$ and radius $r$ ) is assumed to be a circle (with a diameter of $X$ and radius $x$ ). According to the sintering theory, the neck growth is explained by different material transport processes. Theoretical equations for different sintering mechanisms (viscous flow, volume diffusion, grain boundary diffusion, and surface diffusion) have been reported [72], [74,75]. The sintering equations for different sintering mechanisms can be generally expressed as follows [74]:

$$
(x / r)^{n}=B t
$$

where $x / r$ is the ratio of the interparticle neck radius to the particle radius; $B$ is a constant related to geometry, particle size, sintering temperature, and nature of the material; $t$ is the sintering time; and $n$ is a mechanism-dependent exponent determined by the material transport process (viscous flow: $n=2$; volume diffusion: $n=4-5$; grain boundary diffusion: $n=6$; surface diffusion: $n=7$ ).

The exponent $n$ is determined by the sintering mechanism. Therefore, by measuring $n$, the dominant sintering mechanisms of neck growth can be studied. According to Equation (1), a logarithmic formulation of the sintering equation can be derived:

$$
\log (x / r)=(1 / n) \log (t)+(1 / n) \log (B)
$$

Since $B$ is a constant, the inverse slope of the linear fitting between the $\log (x / r)$ and $\log (t)$ values is the exponent $n$. Figure 5 e shows the logarithmic evolution curves of the interparticle neck size ratio $(x / r)$ with sintering time at different sintering temperatures. The solid line is the linear fitting of $\log (x / r)$ and $\log (t)$. Two sintering mechanisms are found. At a sintering temperature of 160,200 , and $250^{\circ} \mathrm{C}$, the values of the inverse slope are $6.7,8.8$, and 8.4 , respectively. Consequently, surface diffusion could be the dominant sintering mechanism at temperatures between $160^{\circ} \mathrm{C}$ and $250{ }^{\circ} \mathrm{C}$. The high specific surface activity of Ag NPs at low sintering temperature contributes the surface diffusion. At higher 
sintering temperature, volume diffusion becomes the dominant diffusion mechanism. The inverse slope of the line at $300{ }^{\circ} \mathrm{C}$ and $350{ }^{\circ} \mathrm{C}$ is 3.7 and 3.8, respectively, which coincide with the characteristic exponent of volume diffusion.

The organics in the Ag NP paste also affect the sintering mechanisms, according to the Fourier-transform (FTIR) spectrum of the Ag NP paste after sintering at different temperatures. The peaks at $2953 \mathrm{~cm}^{-1}$ and $1677 \mathrm{~cm}^{-1}$ correspond to the $\mathrm{C}-\mathrm{H}$ stretch and $\mathrm{C}=\mathrm{O}$ stretch, respectively. After sintering at $160^{\circ} \mathrm{C}$, the characteristic peak of $\mathrm{C}=\mathrm{O}$ is red-shifted to $1633 \mathrm{~cm}^{-1}$. The red shift of the $\mathrm{C}=\mathrm{O}$ peak indicates that the carboxyl oxygen atom of PVP interacts with the Ag NP surface [76]. At sintering temperatures of 300 and $350{ }^{\circ} \mathrm{C}$, the peak at $2893 \mathrm{~cm}^{-1}$ (C-H stretch) disappears, and the peak at $1032 \mathrm{~cm}^{-1}$ (C-N stretch) is significantly weakened. These results indicate that the PVP is decomposed at this sintering temperature. When the temperature is below $250^{\circ} \mathrm{C}$, the PVP was still coated on the Ag NP, and surface diffusion was the dominant sintering mechanism. When the temperature increases to above $300{ }^{\circ} \mathrm{C}$, the PVP in the Ag NP paste is destroyed, and the sintering process changes to volume diffusion. Consequently, the decomposition of organics in the Ag NP paste may affect the sintering mechanism. By adjusting the amount and type of organic components in paste, the sintering behaviors and bondability of $\mathrm{Ag}$ NPs can be controlled. Because the alkylamine will evaporate at $130{ }^{\circ} \mathrm{C}$, using alkylamine as a dispersant will facilitate the sintering process of Ag NPs.

As a key property of the joint, it is important to study the joint strength of the Ag NP paste after sintering. Empirical and theoretical analyses indicate that the microstructures of sintered materials affect the mechanical properties of joints $[77,78]$. Fracturing of joints mainly occurs in the sintered layer. Therefore, the microstructure of the sintered Ag NP paste is related to the joint strength. An obvious fracture is found at the interparticle bonds. The joint strength of Ag NP paste is mainly determined by the sintered bond between contacting Ag NPs [79]. The sphere-sphere model of particle sintering has been used to analyze the sintering mechanism of NPs as well as the relationship between the strength and microstructure. The joint strength depends on the intrinsic material strength and the ratio of the sintered neck area to the cross-section area through the spherical center. In order to determine the relationship between the joint strength of the Ag NP paste and the ratio of the sintered neck area to the cross-section area through the spherical center, a sintering joint experiment was carried out at a temperature of $250-300{ }^{\circ} \mathrm{C}$, and the relationship between the micromorphology of the Ag NP joint and the joint strength was analyzed (Figure 5f). It can be seen that there is a linear relationship between the strength of the Ag NP joint and $(x / r)^{2}$, which represents the size of the sintering neck. According to the sintering model, it can be concluded that the degree of joint bonding between adjacent particles after sintering is one of the main sources of strength. It can be inferred that a higher interface connection ratio leads to higher joint strength [80].

\subsection{High-Temperature Joint Properties of Ag NP Pastes}

The metal NPs have a high specific surface activity, and thus show a low sintering temperature. This type of high-performance bonding material is suitable for both highand low-temperature bonding environments and has broad application prospects. At present, the bonding material is often used for devices in high-temperature environments and broadband gap semiconductor devices $[62,65-67,81]$. Therefore, it is interesting to study the high-temperature properties of joints utilizing polyol-based Ag NP paste. For this reason, the joint bonded with Ag NP paste was stored at temperatures of $200-350^{\circ} \mathrm{C}$ for $50 \mathrm{~h}$ before evaluating the joint properties [82]. The results indicate that the hightemperature properties of the joint bonded with Ag NP paste are superior to those of a joint in which $\mathrm{Pb}_{95} \mathrm{Sn}_{5}$ was applied.

The influence of temperature, which ranges from $200-350{ }^{\circ} \mathrm{C}$, on the shear strength of the joints bonded with $\mathrm{Pb}_{95} \mathrm{Sn}_{5}$ solder and $\mathrm{Ag} \mathrm{NP}$ paste are shown in Figure 6a. The strength of the joints using Ag NP paste rises after heat treatment at 250,300 , and $350{ }^{\circ} \mathrm{C}$, which can be attributed to the further sintering. The neck growth and grain growth 
observed in the fracture microstructures can also explain the strength increase of the joint bonded with Ag NP paste (Figure 6b-e). The strength of the joint bonded with $\mathrm{Pb}_{95} \mathrm{Sn}_{5}$ solder does not noticeably change until the temperature rises to $350{ }^{\circ} \mathrm{C}$, when the strength decreases to 0 and the joint disconnects. Through EDX analysis, $\mathrm{Sn}, \mathrm{Ag}, \mathrm{Cu}$, and $\mathrm{O}$ were detected on the surface of the disconnected joint, which implies the breakage of the $\mathrm{Ni} / \mathrm{Ag}$ layer plated on the $\mathrm{Cu}$ substrate and the occurrence of oxidation. This is due to the fact that $350{ }^{\circ} \mathrm{C}$ is higher than the melting point. Paknejad et al. summarized the shear strengths of joints using Ag NP paste after heat treatment and found that the strength increases at a treatment temperature below $300^{\circ} \mathrm{C}$ in most situations [83]. However, if the temperature is too high, oxygen may penetrate into the sintered $\mathrm{Ag}$ due to its porous structure. For example, the $\mathrm{Cu}$ substrate without a plated layer can oxidize within $24 \mathrm{~h}$ at $300{ }^{\circ} \mathrm{C}$ [84]. The collective results suggest that the joint bonded with Ag NP paste has good hightemperature properties, which are likely superior to those of the joint coated with $\mathrm{Pb}_{95} \mathrm{Sn}_{5}$ solder. In addition, the Ag NP paste has some other advantages compared with the other commonly used interconnection materials. Table 3 summarizes the property comparison of some commonly used solder alloys with the Ag NP paste.

Table 3. Property comparison of some commonly used solder alloys with Ag NP pastes. Reprinted/Adapted with the permission from Zhang, P (2018). Copyright 2018 Elsevier Ltd. [70].

\begin{tabular}{ccccc}
\hline & $\mathbf{P b}_{\mathbf{3 7}} \mathbf{S n}_{\mathbf{6 3}}$ & $\mathbf{S n}_{\mathbf{9 6 . 5}} \mathbf{A g}_{\mathbf{3 . 5}}$ & $\mathbf{A u}_{\mathbf{8 0}} \mathbf{S n}_{\mathbf{2 0}}$ & $\mathbf{A g} \mathbf{~ N P} \mathbf{P a s t e s}$ \\
\hline Bonding mechanism & Liquidus reflow & Liquidus reflow & Liquidus reflow & Sintering \\
Maximum use temperature $\left({ }^{\circ} \mathrm{C}\right)$ & 180 & 220 & 280 & 960 \\
Electrical conductivity $\times 10^{5}(\Omega \mathrm{cm})$ & 0.69 & 0.82 & 0.62 & 2.6 \\
Thermal conductivity $(\mathrm{W} / \mathrm{mK})$ & 51 & 60 & 26 & 68 \\
Elastic modulus $(\mathrm{GPa})$ & 16 & 22.5 & $\mathrm{~N} / \mathrm{A}$ & 10 \\
Yield strength $(\mathrm{MPa})$ & 27 & 52 & 275 & 43 \\
Tensile strength $(\mathrm{MPa})$ & 27 & & 43 \\
\hline
\end{tabular}
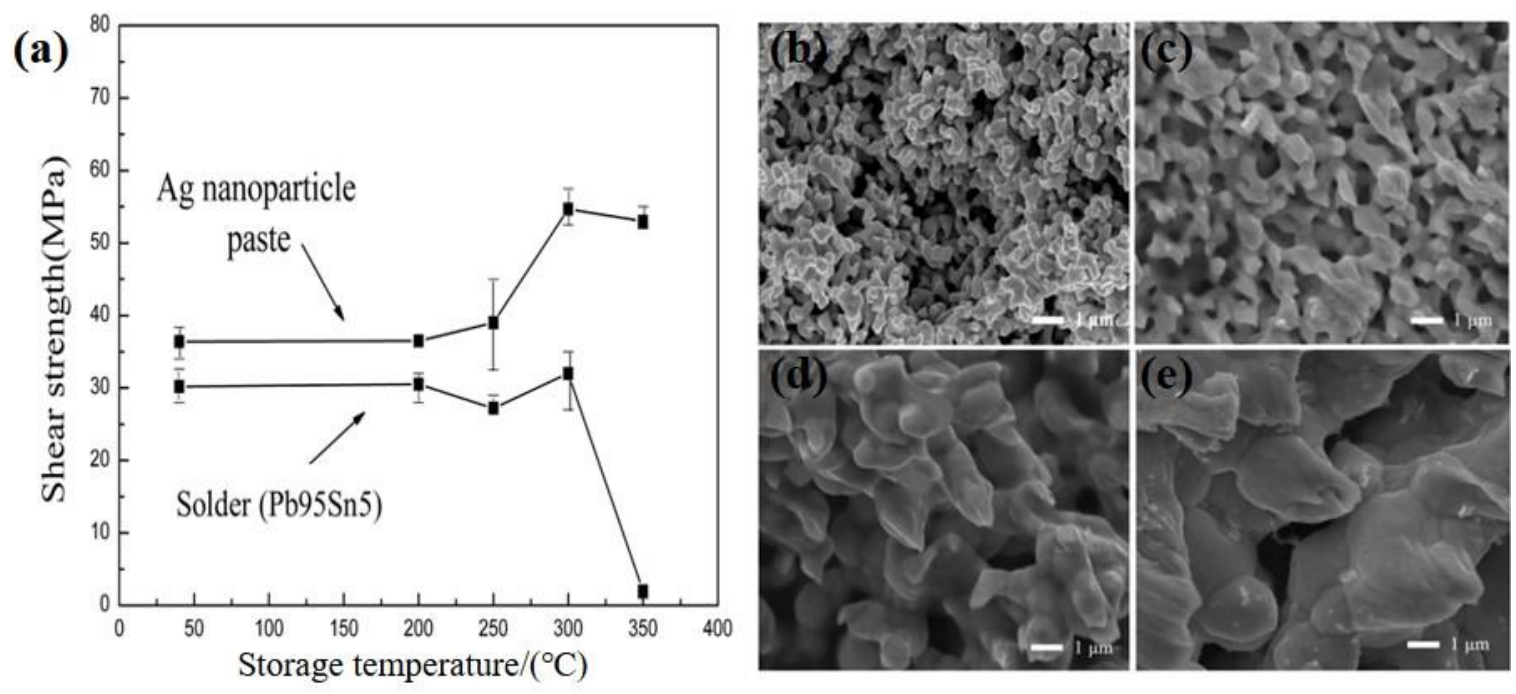

Figure 6. (a) Comparison of the joint strength using $\mathrm{Ag} \mathrm{NP}$ paste and $\mathrm{Pb}_{95} \mathrm{Sn}_{5}$ solder after storage at different temperatures for $50 \mathrm{~h}$. SEM fracture surfaces of the joints using Ag NP paste at different temperatures of (b) 200, (c) 250, (d) 300 and (e) $350{ }^{\circ} \mathrm{C}$. Reprinted/Adapted with the permission from Yan, J (2016). Copyright 2016 Hindawi Publishing [82].

\section{Summary and Future Trends}

This review summarized our research progress on the sintering-bonding technology using Ag NPs for electronic packaging applications. A low-temperature bonding method using polyol-based Ag NPs was developed. The deposition behavior of the NP layer related to the coffee ring effect was studied. Strong joints were formed using Ag pastes. The 
reduction of organic components in the paste was helpful for achieving low-temperature bonding. The classical sphere-sphere model was introduced to investigate the sintering mechanisms of Ag NPs during the sintering process. Different sintering mechanisms, which could be related to the decomposition of organic components, were revealed at different sintering temperatures. The joints bonded with Ag NP pastes showed good resistance to high temperature, indicating that the Ag NP paste could be used in hightemperature environments. This interconnection technology using metal NP pastes has shown potential application for electronic packaging. More researches should be carried out to further promote the applications in the future:

(1) Generally, in order to obtain robust joints with a high shear strength, the sinteringbonding process is usually carried out with an auxiliary pressure, which limits widespread applications, especially in flexible electronic devices. Future work needs to focus on reducing the pressure applied on chips during the sintering processes.

(2) The bonding between NP pastes and metal substrates is a complicated process, which relies on multiple factors, such as organic components, sintering temperature, pressure, and paste deposition distribution. Future work needs to focus on the interfacial reactions between NP pastes and metal base during the sintering processes.

(3) The classical sphere-to-sphere models are usually used to investigate the sinteringbonding mechanism of NP pastes. For other pastes which have various morphologies, the sintering-bonding mechanism could be different. Future work needs to focus on the study of the theoretical models.

Funding: This research was funded by the National Natural Science Foundation of China (51775303, 52075289).

Institutional Review Board Statement: Not applicable.

Informed Consent Statement: Not applicable.

Data Availability Statement: The data presented in this study are available in article.

Conflicts of Interest: The authors hereby state that there is no conflict of interest related to the work.

\section{References}

1. Chen, C.; Suganuma, K. Microstructure and mechanical properties of sintered Ag particles with flake and spherical shape from nano to micro size. Mater. Des. 2019, 162, 311-321. [CrossRef]

2. Navarro, L.A.; Perpina, X.; Godignon, P.; Montserrat, J.; Banu, V.; Vellvehi, M.; Jorda, X. Thermomechanical Assessment of Die-Attach Materials for Wide Bandgap Semiconductor Devices and Harsh Environment Applications. IEEE Trans. Power Electron. 2013, 29, 2261-2271. [CrossRef]

3. Kong, Y.-F.; Li, X.; Mei, Y.-H.; Lu, G.-Q. Effects of Die-Attach Material and Ambient Temperature on Properties of High-Power COB Blue LED Module. IEEE Trans. Electron. Devices 2015, 62, 2251-2256. [CrossRef]

4. Hong, W.S.; Kim, M.S.; Kim, D.; Oh, C. Silver Sintered Joint Property between Silicon Carbide Device and Ceramic Substrate for Electric Vehicle Power Module. J. Electron. Mater. 2018, 48, 122-134. [CrossRef]

5. Tan, K.S.; Wong, Y.H.; Cheong, K.Y. Thermal characteristic of sintered Ag-Cu nanopaste for high-temperature die-attach application. Int. J. Therm. Sci. 2015, 87, 169-177. [CrossRef]

6. Shen, W.; Zhang, X.; Huang, Q.; Xu, Q.; Song, W. Preparation of solid silver nanoparticles for inkjet printed flexible electronics with high conductivity. Nanoscale 2014, 6, 1622-1628. [CrossRef] [PubMed]

7. Zhang, W.; Chen, J.; Deng, Z.; Liu, Z.; Huang, Q.; Guo, W.; Huang, J. The pressureless sintering of micron silver paste for electrical connections. J. Alloys Compd. 2019, 795, 163-167. [CrossRef]

8. Yan, J.; Zou, G.; Wu, A.P.; Ren, J.; Yan, J.; Hu, A.; Zhou, Y. Pressureless bonding process using Ag nanoparticle paste for flexible electronics packaging. Scr. Mater. 2012, 66, 582-585. [CrossRef]

9. Jiang, Q.; Zhang, S.; Li, J. Grain size-dependent diffusion activation energy in nanomaterials. Solid State Commun. 2004, 130, 581-584. [CrossRef]

10. Kim, M.I.; Choi, E.B.; Leea, J.-H. Improved sinter-bonding properties of silver-coated copper flake paste in air by the addition of sub-micrometer silver-coated copper particles. J. Mater. Res. Technol. 2020, 9, 16006-16017. [CrossRef]

11. Moon, K.-S.; Dong, H.; Maric, R.; Pothukuchi, S.; Hunt, A.; Li, Y.; Wong, C.P. Thermal behavior of silver nanoparticles for low-temperature interconnect applications. J. Electron. Mater. 2005, 34, 168-175. [CrossRef]

12. Zhang, M.; Efremov, M.Y.; Schiettekatte, F.; Olson, E.A.; Kwan, A.T.; Lai, S.L.; Wisleder, T.; Greene, J.E.; Allen, L.H. Size-dependent melting point depression of nanostructures: Nanocalorimetric measurements. Phys. Rev. B 2000, 62, 10548-10557. [CrossRef] 
13. Yan, J.; Zou, G.; Zhang, Y.; Li, J.; Liu, L.; Wu, A.; Zhou, Y.N. Metal-Metal Bonding Process Using Cu + Ag Mixed Nanoparticles. Mater. Trans. 2013, 54, 879-883. [CrossRef]

14. Yan, J.; Zou, G.; Wu, A.; Ren, J.; Hu, A.; Zhou, Y.N. Polymer-Protected Cu-Ag Mixed NPs for Low-Temperature Bonding Application. J. Electron. Mater. 2012, 41, 1886-1892. [CrossRef]

15. Ko, S.H.; Pan, H.; Grigoropoulos, C.P.; Luscombe, C.K.; Fréchet, J.M.J.; Poulikakos, D. All-inkjet-printed flexible electronics fabrication on a polymer substrate by low-temperature high-resolution selective laser sintering of metal nanoparticles. Nanotechnology 2007, 18, 345202. [CrossRef]

16. Cui, Q.; Gao, F.; Mukherjee, S.; Gu, Z. Joining and Interconnect Formation of Nanowires and Carbon Nanotubes for Nanoelectronics and Nanosystems. Small 2009, 5, 1246-1257. [CrossRef] [PubMed]

17. Decharat, A.; Wagle, S.; Jacobsen, S.; Melandsø, F. Using Silver Nano-Particle Ink in Electrode Fabrication of High Frequency Copolymer Ultrasonic Transducers: Modeling and Experimental Investigation. Sensors 2015, 15, 9210-9227. [CrossRef]

18. Huang, Q.; Shen, W.; Xu, Q.; Tan, R.; Song, W. Properties of polyacrylic acid-coated silver nanoparticle ink for inkjet printing conductive tracks on paper with high conductivity. Mater. Chem. Phys. 2014, 147, 550-556. [CrossRef]

19. Yan, J.; Zou, G.; Hu, A.; Zhou, Y.N. Preparation of PVP coated Cu NPs and its applications for Low-Temperature Bonding. J. Mater. Chem. 2011, 21, 15981-15986.

20. Hu, A.; Guo, J.Y.; Alarifi, H.; Patane, G.; Zhou, Y.; Compagnini, G.; Xu, C.X. Low temperature sintering of Ag nanoparticles for flexible electronics packaging. Appl. Phys. Lett. 2010, 97, 153117. [CrossRef]

21. Lu, Y.; Huang, J.Y.; Wang, C.; Sun, S.; Lou, J. Cold welding of ultrathin gold nanowires. Nat. Nanotechnol. 2010, 5, 218-224. [CrossRef]

22. Ide, E.; Angata, S.; Hirose, A.; Kobayashi, K. Metal-metal bonding process using Ag metallo-organic nanoparticles. Acta Mater. 2005, 53, 2385-2393. [CrossRef]

23. Maruyama, M.; Matsubayashi, R.; Iwakuro, H.; Isoda, S.; Komatsu, T. Silver nanosintering: A lead-free alternative to soldering. Appl. Phys. A 2008, 93, 467-470. [CrossRef]

24. Morita, T.; Ide, E.; Yasuda, Y.; Hirose, A.; Kobayashi, K. Study of Bonding Technology Using Silver Nanoparticles. Jpn. J. Appl. Phys. 2008, 47, 6615-6622. [CrossRef]

25. Bai, J.G.; Guo-Quan, L. Thermomechanical Reliability of Low-Temperature Sintered Silver Die Attached SiC Power Device Assembly. IEEE Trans. Device Mater. Reliab. 2006, 6, 436-441. [CrossRef]

26. Akada, Y.; Tatsumi, H.; Yamaguchi, T.; Hirose, A.; Morita, T.; Ide, E. Interfacial Bonding Mechanism Using Silver Metallo-Organic Nanoparticles to Bulk Metals and Observation of Sintering Behavior. Mater. Trans. 2008, 49, 1537-1545. [CrossRef]

27. Yan, J.; Zou, G.; Wu, A.; Ren, J.; Yan, J.; Hu, A.; Liu, L.; Zhou, Y.N. Effect of PVP on the low temperature bonding process using polyol prepared Ag nanoparticle paste for electronic packaging application. J. Phys. Conf. Ser. 2012, 379, 012024. [CrossRef]

28. Fang, H.; Wang, C.; Zhou, S.; Kang, Q.; Wang, T.; Yang, D.; Tian, Y.; Suga, T. Rapid pressureless and low-temperature bonding of large-area power chips by sintering two-step activated Ag paste. J. Mater. Sci. Mater. Electron. 2020, 31, 6497-6505. [CrossRef]

29. Zhang, S.; Xu, X.; Lin, T.; He, P. Recent advances in nano-materials for packaging of electronic devices. J. Mater. Sci. Mater. Electron. 2019, 30, 13855-13868. [CrossRef]

30. Sun, Y.; Xia, Y. Shape-Controlled Synthesis of Gold and Silver Nanoparticles. Science 2003, 34, 2176-2179. [CrossRef]

31. Suriati, G.; Mariatti, M.; Azizan, A. Synthesis of Silver Nanoparticles by Chemical Reduction Method: Effect of Reducing Agent and Surfactant Concentration. Int. J. Automot. Mech. Eng. 2014, 10, 1920-1927. [CrossRef]

32. Krajczewski, J.; Joubert, V.; Kudelski, A. Light-induced transformation of citrate-stabilized silver nanoparticles: Photochemical method of increase of SERS activity of silver colloids. Colloids Surf. A Physicochem. Eng. Asp. 2014, 456, 41-48. [CrossRef]

33. Krajczewski, J.; Kołąaj, K.; Kudelski, A. Light-induced growth of various silver seed nanoparticles: A simple method of synthesis of different silver colloidal SERS substrates. Chem. Phys. Lett. 2015, 625, 84-90. [CrossRef]

34. Park, S.H.; Son, J.G.; Lee, T.G.; Park, H.M.; Song, J.Y. One-step large-scale synthesis of micrometer-sized silver nanosheets by a template-free electrochemical method. Nanoscale Res. Lett. 2013, 8, 248. [CrossRef]

35. Lu, Y.D.; Chen, X.X.; Chen, L.H. Applied Mechanics and Materials; Trans Tech Publications: Bäch, Switzerland, $2020 ;$ pp. $158-161$.

36. Zhu, D.; Yan, J.; Xie, J. Reshaping enhancement of gold nanorods by femtosecond double-pulse laser. Opt. Lett. 2020, 45, 1758-1761. [CrossRef] [PubMed]

37. Yan, J.; Zhu, D.; Xie, J.; Shao, Y.; Xiao, W. Light Tailoring of Internal Atomic Structure of Gold Nanorods. Small 2020, 16, 2001101. [CrossRef] [PubMed]

38. Jia, Q.; Zou, G.; Wang, W.; Ren, H.; Zhang, H.; Deng, Z.; Feng, B.; Liu, L. Sintering Mechanism of a Supersaturated Ag-Cu Nanoalloy Film for Power Electronic Packaging. ACS Appl. Mater. Interfaces 2020, 12, 16743-16752. [CrossRef]

39. Qiao, M.; Yan, J.; Qu, L.; Zhao, B.; Yin, J.; Cui, T.; Jiang, L. Femtosecond Laser Induced Phase Transformation of TiO 2 with Exposed Reactive Facets for Improved Photoelectrochemistry Performance. ACS Appl. Mater. Interfaces 2020, 12, 41250-41258. [CrossRef]

40. Kim, K.-S.; Park, B.-G.; Jung, K.-H.; Kim, J.-W.; Jeong, M.Y.; Jung, S.-B. Microwave Sintering of Silver Nanoink for Radio Frequency Applications. J. Nanosci. Nanotechnol. 2015, 15, 2333-2337. [CrossRef]

41. Wei, C.; Li, M.; Zhao, X. Surface-Enhanced Raman Scattering (SERS) with Silver Nano Substrates Synthesized by Microwave for Rapid Detection of Foodborne Pathogens. Front. Microbiol. 2018, 9, 2857. [CrossRef]

42. Ledrappier, F. Research of nano-silver colloids prepared by microwave-assisted synthesis method and its fresh-keeping of strawberry. Sci. Technol. Food Ind. 2014, 35, 326-327. 
43. Li, Y.; Jing, H.; Han, Y.; Xu, L.; Lu, G. Microstructure and Joint Properties of Nano-Silver Paste by Ultrasonic-Assisted Pressureless Sintering. J. Electron. Mater. 2016, 45, 3003-3012. [CrossRef]

44. Zhang, W.; Zhang, W.; Qiao, X.; Qiu, X.; Chen, Q.; Cai, Y. Controllable preparation of silver nanostructures and the effects of acidity-basicity of the reaction system. Sci. Adv. Mater. 2014, 6, 304-311. [CrossRef]

45. Bai, J.; Zhang, Z.; Calata, J.; Lu, G. 2005 Conference on High Density Microsystem Design and Packaging and Component Failure Analysis, IEEE: New York, NY, USA, 2005; pp. 1-5.

46. Kahler, J.; Heuck, N.; Wagner, A.; Stranz, A.; Peiner, E.; Waag, A. Sintering of Copper Particles for Die Attach. IEEE Trans. Compon. Packag. Manuf. Technol. 2012, 2, 1587-1591. [CrossRef]

47. Manikam, V.R.; Razak, K.A.; Cheong, K.Y. Sintering of Silver-Aluminum Nanopaste with Varying Aluminum Weight Percent for Use as a High-Temperature Die-Attach Material. IEEE Trans. Compon. Packag. Manuf. Technol. 2012, 2, 1940-1948. [CrossRef]

48. Zeng, G.; McDonald, S.; Nogita, K. Development of high-temperature solders: Review. Microelectron. Reliab. 2012, 52, 1306-1322. [CrossRef]

49. Manikam, V.R.; Cheong, K.Y. Die Attach Materials for High Temperature Applications: A Review. IEEE Trans. Compon. Packag. Manuf. Technol. 2011, 1, 457-478. [CrossRef]

50. Abtew, M.; Selvaduray, G. Lead-free Solders in Microelectronics. Mater. Sci. Eng. R Rep. 2000, 27, 95-141. [CrossRef]

51. Siow, K.S.; Chua, S.T. Thermal Ageing Studies of Sintered Micron-Silver (Ag) Joint as a Lead-Free Bonding Material. Met. Mater. Int. 2020, 26, 1404-1414. [CrossRef]

52. Ogura, H.; Maruyama, M.; Matsubayashi, R.; Ogawa, T.; Nakamura, S.; Komatsu, T.; Nagasawa, H.; Ichimura, A.; Isoda, S. Carboxylate-Passivated Silver Nanoparticles and Their Application to Sintered Interconnection: A Replacement for High Temperature Lead-Rich Solders. J. Electron. Mater. 2010, 39, 1233-1240. [CrossRef]

53. Lei, T.G.; Calata, J.N.; Guo-Quan, L.; Xu, C.; Shufang, L. Low-Temperature Sintering of Nanoscale Silver Paste for Attaching Large-Area $\left(>100 \mathrm{~mm}^{2}\right)$ Chips. Components and Packaging Technologies. IEEE Trans. Compon. Packag. Technol. 2010, 33, 98-104. [CrossRef]

54. Alarifi, H.; Hu, A.; Yavuz, M.; Zhou, Y.N. Silver Nanoparticle Paste for Low-Temperature Bonding of Copper. J. Electron. Mater. 2011, 40, 1394-1402. [CrossRef]

55. Zou, G.; Yan, J.; Mu, F.; Wu, A.; Ren, J.; Hu, A. Low Temperature Bonding of Cu Metal through Sintering of Ag Nanoparticles for High Temperature Electronic Application. Open Surf. Sci. J. 2010, 3, 70-75. [CrossRef]

56. Yan, J.; Zou, G.; Wu, A.; Ren, J.; Hu, A.; Zhou, Y.N. Improvement of Bondability by Depressing the Inhomogeneous Distribution of Nanoparticles in a Sintering Bonding Process with Silver Nanoparticles. J. Electron. Mater. 2012, 41, 1924-1930. [CrossRef]

57. Deegan, R.D.; Bakajin, O.; Dupont, T.F.; Huber, G.; Nagel, S.R.; Witten, T.A. Capillary flow as the cause of ring stains from dried liquid drops. Nat. Cell Biol. 1997, 389, 827-829. [CrossRef]

58. Deegan, R.D.; Bakajin, O.; Dupont, T.F.; Huber, G.; Nagel, S.R.; Witten, T.A. Contact line deposits in an evaporating drop. Phys. Rev. E 2000, 62, 756-765. [CrossRef]

59. Hu, H.; Larson, R.G. Marangoni Effect Reverses Coffee-Ring Depositions. J. Phys. Chem. B 2006, 110, 7090-7094. [CrossRef]

60. Pesach, D.; Marmur, A. Marangoni effects in the spreading of liquid mixtures on a solid. Langmuir 1987, 3, 519-524. [CrossRef]

61. Hasnaoui, A.; Van Swygenhoven, H.; Derlet, P.M. Dimples on Nanocrystalline Fracture Surfaces as Evidence for Shear Plane Formation. Science 2003, 300, 1550-1552. [CrossRef]

62. Bai, J.G.; Zhang, Z.Z.; Calata, J.N.; Lu, G.-Q. Low-Temperature Sintered Nanoscale Silver as a Novel Semiconductor DeviceMetallized Substrate Interconnect Material. IEEE Trans. Components Packag. Technol. 2006, 29, 589-593. [CrossRef]

63. Bakhishev, T.; Subramanian, V. Investigation of Gold Nanoparticle Inks for Low-Temperature Lead-Free Packaging Technology. J. Electron. Mater. 2009, 38, 2720-2725. [CrossRef]

64. Lu, Y.; Liu, G.L.; Lee, L.P. High-Density Silver Nanoparticle Film with Temperature-Controllable Interparticle Spacing for a Tunable Surface Enhanced Raman Scattering Substrate. Nano Lett. 2005, 5, 5-9. [CrossRef] [PubMed]

65. Johnson, R.; Evans, J.; Jacobsen, P.; Thompson, J.; Christopher, M. The Changing Automotive Environment: High-Temperature Electronics. IEEE Trans. Electron. Packag. Manuf. 2004, 27, 164-176. [CrossRef]

66. Desplats, H.; Brisson, E.; Rogeon, P.; Carré, P.; Bonhomme, A. Pressureless sintering behavior and properties of Ag-SnO 2 . Rare Met. 2019, 38, 35-41. [CrossRef]

67. Zhang, Z.L.; Wang, B.; Chen, Y.; Tang, Y.H.; Song, X.M.; Li, Q.L.; Yan, H. Ag nanoparticles assisted chemical etching for the preparation of pyramid-SiNWs binary structure. Rare Met. 2019, 38, 312-315. [CrossRef]

68. Jiang, H.; Moon, K.-S.; Li, Y.; Wong, C.P. Surface Functionalized Silver Nanoparticles for Ultrahigh Conductive Polymer Composites. Chem. Mater. 2006, 18, 2969-2973. [CrossRef]

69. Zhang, R.; Lin, W.; Moon, K.-S.; Wong, C.P. Fast Preparation of Printable Highly Conductive Polymer Nanocomposites by Thermal Decomposition of Silver Carboxylate and Sintering of Silver Nanoparticles. ACS Appl. Mater. Interfaces 2010, 2, 2637-2645. [CrossRef]

70. Zhang, P.; Jiang, X.; Yuan, P.; Yan, H.; Yang, D. Silver nanopaste: Synthesis, reinforcements and application. Int. J. Heat Mass Transf. 2018, 127, 1048-1069. [CrossRef]

71. Yan, J.; Zou, G.; Liu, L.; Zhang, D.; Bai, H.; Wu, A.-P.; Zhou, Y.N. Sintering mechanisms and mechanical properties of joints bonded using silver nanoparticles for electronic packaging applications. Weld. World 2015, 59, 427-432. [CrossRef]

72. Frenkel, J. Viscous flow of crystalline bodies under the action of surface tension. J. Phys. 1945, 9, 385-391. 
73. Shaler, A.J.; Wulff, J. Mechanism of Sintering. Ind. Eng. Chem. 1948, 40, 838-842. [CrossRef]

74. Kuczynski, G.C. Self-diffusion in sintering of metallic particles. JOM 1949, 1, 169-178. [CrossRef]

75. Rockland, J. The determination of the mechanism of sintering. Acta Met. 1967, 15, 277-286. [CrossRef]

76. Zhang, Z.; Zhao, B.; Hu, L. PVP Protective Mechanism of Ultrafine Silver Powder Synthesized by Chemical Reduction Processes. J. Solid State Chem. 1996, 121, 105-110. [CrossRef]

77. Nyce, A.C.; Shafer, W.M. The relationship of B.E.T surface area to the sintering behavior of spherical copper particles. Int. J. Powder Metall. 1972, 8, 171-180.

78. German, R.M. Manipulation of Strength during Sintering as a Basis for Obtaining Rapid Densification without Distortion. Mater. Trans. 2001, 42, 1400-1410. [CrossRef]

79. Liu, W.; An, R.; Wang, C.; Zheng, Z.; Tian, Y.; Xu, R.; Wang, Z. Recent Progress in Rapid Sintering of Nanosilver for Electronics Applications. Micromachines 2018, 9, 346. [CrossRef]

80. Chen, C.; Zhang, Z.; Wang, Q.; Zhang, B.; Gao, Y.; Sasamura, T.; Oda, Y.; Ma, N.; Suganuma, K. Robust bonding and thermal-stable $\mathrm{Ag}-\mathrm{Au}$ joint on ENEPIG substrate by micron-scale sinter Ag joining in low temperature pressure-less. J. Alloys Compd. 2020, 828, 154397. [CrossRef]

81. Yan, J.; Zhang, D.; Zou, G.; Liu, L.; Zhou, Y.N. Preparation of Oxidation-Resistant Ag-Cu Alloy Nanoparticles by Polyol Method for Electronic Packaging. J. Electron. Mater. 2018, 48, 1286-1293. [CrossRef]

82. Yan, J.; Zhang, D.; Zou, G.; Liu, L.; Bai, H.; Wu, A.; Zhou, Y.N. Sintering Bonding Process with Ag Nanoparticle Paste and Joint Properties in High Temperature Environment. J. Nanomater. 2016, 2016, 5284048. [CrossRef]

83. Paknejad, S.A.; Mannan, S.H. Review of silver nanoparticle based die attach materials for high power/temperature applications. Microelectron. Reliab. 2017, 70,1-11. [CrossRef]

84. Chua, S.; Siow, K. Microstructural studies and bonding strength of pressureless sintered nano-silver joints on silver, direct bond copper (DBC) and copper substrates aged at $300^{\circ} \mathrm{C}$. J. Alloys Compd. 2016, 687, 486-498. [CrossRef] 